\title{
REVIEW
}

\section{Protective measures against ultrafiltration failure in peritoneal dialysis patients}

\author{
Anna Rita Aguirre, Hugo Abensur \\ Hospital das Clínicas da Faculdade de Medicina da Universidade de São Paulo, Nephrology Division, São Paulo/SP, Brazil.
}

Ultrafiltration failure in patients undergoing peritoneal dialysis is a condition with an incidence that increases over time. It is related to increased cardiovascular morbidity and mortality and is a major cause of the abandonment of the treatment technique. Because the number of patients undergoing renal replacement therapy is increasing with society aging and because approximately $10 \%$ of this population is treated with peritoneal dialysis, this matter is becoming more common in everyday practice for clinicians involved in the care of patients with chronic renal failure. In this review, we summarize the available measures used to prevent and treat ultrafiltration failure and the current state of research in the field, both in the experimental and clinical settings, focusing on the possible clinical applications of recent findings.

KEYWORDS: Peritoneal membrane; Peritoneal dialysis fluids; Peritoneal fibrosis; End-stage renal disease; Ultrafiltration.

Aguirre AR, Abensur H. Protective measures against ultrafiltration failure in peritoneal dialysis patients. Clinics. 2011;66(12):2151-2157.

Received for publication on June 28, 2011; First review completed on August 6, 2011; Accepted for publication on August 18, 2011

E-mail: annaritanefro@gmail.com

Tel.: $55112661-7629$

\section{INTRODUCTION}

Peritoneal dialysis (PD) is an effective therapeutic strategy for managing both acute and chronic kidney disease (CKD) and has been employed as a renal replacement therapy (RRT) modality for CKD for the last five decades. ${ }^{1}$ During this time, technical improvements have led to reduced morbidity and mortality rates. In the last decade, better outcomes have been noted with PD, whereas mortality rates have remained stable with hemodialysis (HD). ${ }^{2}$ However, the percentage of patients who begin RRT with PD remains approximately $10 \%$ worldwide, ${ }^{3}$ and although PD and HD should be considered as complementary therapy modalities, PD is not routinely offered to incident patients.

Over the last century, our understanding of the mechanisms involved in solute and fluid transport across the peritoneal membrane (PM) has improved, and this growing knowledge has allowed apparatus development and PD prescription in consonance with peritoneal physiology. "Pore theory," the dynamics of molecular transport through the PM, basically considers three pore sizes in the walls of submesothelial capillaries through which molecules can travel. A minority of the pores, with diameters of $250 \AA$, are called large pores and allow the movement of proteins across the PM. Most small solutes can pass through the small pores,

Copyright (c) 2011 CLINICS - This is an Open Access article distributed under the terms of the Creative Commons Attribution Non-Commercial License (http:// creativecommons.org/licenses/by-nc/3.0/) which permits unrestricted noncommercial use, distribution, and reproduction in any medium, provided the original work is properly cited.

No potential conflict of interest was reported. which have diameters of $43 \AA$. Aquaporin-1 (AQP1) has also been identified in the $\mathrm{PM}^{6}$ and has been called "ultrapore" or "ultrasmall pore" because only water molecules can move through it. Forty percent of the osmosis during the first 4 hours of a dwell duration is attributed to transport through AQP1. The fluxes through these channels are dependent on the Starling forces that act in the peritoneal cavity and blood compartments, and more recently, importance has been assigned to the distance of each pore from the cavity, which is referred to as the "distributive model."

Because of longer patient survival, PD is used for increasingly long periods. Dysfunctions in the peritoneal transport system have been found to develop over time, with the most prevalent problem being ultrafiltration failure (UFF).

\section{Ultrafiltration failure}

UFF, which can be defined as ultrafiltration (UF) of less than $400 \mathrm{~mL}$ after a 4-hour dwell duration with a $4.25 \%$ dextrose-based peritoneal dialysis fluid (PDF), is a clinical condition that has an increasing incidence with chronic PD duration. Thirty to fifty percent of patients develop UFF after 6 years of PD, and in $24 \%$ of cases, changing the RRT modality is required to maintain clinical stability. ${ }^{8,9}$

Signs and symptoms of fluid overload, such as high arterial pressure, pulmonary congestion and a worsening of cardiac function are the usual manifestations of UFF, and a differentiation from the loss of residual renal function (RRF) or dietary noncompliance is necessary. To this end, measuring the UF volume after 4 hours is of great value. ${ }^{10,11}$

Morbidity and mortality rates have been shown to be significantly higher among PD patients with UFF; ${ }^{12,13}$ these higher morbidity and mortality rates have been attributed to 
excess fluid and its effects on the cardiovascular system, such as arterial hypertension and left ventricular hypertrophy. ${ }^{14}$ Atrial natriuretic peptide and brain natriuretic peptide have been studied in PD patients as markers of volume overload, and high levels of each have been linked to an eight-fold increase in mortality relative to patients with low levels. ${ }^{15}$ Also important is the correlation between insulin resistance and metabolic syndrome with the fast peritoneal transport, ${ }^{17}$ since these metabolic changes can potentially contribute to the development of cardiovascular disease. ${ }^{16}$ Therefore, prevention, early identification, and proper clinical management of UFF are crucial elements of cardiovascular risk reduction strategies.

UFF generally develops as the result of one or more of the following phenomena: a significant increase in the peritoneal vascular surface area, a decrease in the osmotic conductance of the PM, increased lymphatic absorption, and the reduction of the peritoneal surface area by scars or adhesions. $^{18}$

Uremia, ${ }^{19}$ infectious peritonitis, ${ }^{20}$ high glucose concentrations in $\mathrm{PDF}^{21}$ glucose degradation products (GDPs) formed during heat sterilization, ${ }^{22}$ and the generation of advanced glycation end-products (AGEs) ${ }^{23}$ have all been implicated in UFF development. These factors are primarily related to chronic and acute inflammation of the peritoneum, ${ }^{24}$ which in turn leads to local neoangiogenesis, vasculopathy, the epithelial-to-mesenchymal transition (EMT) of mesothelial cells ${ }^{25}$ and collagen deposition in the compact submesothelial zone with subsequent PM thickening. ${ }^{26}$ These morphological changes translate clinically into faster small-solute transport with rapid vanishing of the osmotic gradient between the blood and the cavity and diminished osmotic conductance of the membrane, meaning that there is less osmosis even though a gradient is present. Both effects are associated with a functional decline in the peritoneum as a dialyzing membrane. There is evidence that the decrease in the peritoneal osmotic conductance is related to AQP1 dysfunction $^{27}$ and that the acceleration of small-solute transfer is related to the thickening of the collagen layer and high vascular density.

A rare, though dramatic, clinical condition also associated with the loss of dialyzing and UF capacity is known as sclerosing peritonitis, encapsulating sclerosing peritonitis (ESP) or abdominal cocoon. One possible explanation for the development of this condition is a "two-hit" model, in which a denuded, thickened PM resulting from longterm PD undergoes a second inflammatory insult. ${ }^{28}$ These second stimuli, even when very slight, could trigger the development of ESP in a severely damaged peritoneum, while a less-damaged membrane would likely require more potent stimuli. The most characteristic feature of ESP is the formation of a peritoneal capsule as the result of the deposition and organization of fibrin, which are likely the key events in ESP's pathogenesis. The fibrin seems to derive from increased plasma exudation from the peritoneal microvessels, and the adhesion of the peritoneum causes serious intestinal immobility, thus resulting in ileus. $^{29}$

However, some researchers believe this condition to be a separate nosological entity as opposed to a further stage of progressive peritoneal damage caused by bio-incompatible PDFs. ${ }^{30}$ These researchers argue that the different natural history, the association with autoimmune diseases ${ }^{31}$ and the frequent occurrence in individuals not being treated with $\mathrm{PD}$ and even in other species favor this hypothesis. In addition, animal models for these conditions require different aggressors to be simulated. ${ }^{32}$ In this hypothesis, PD would act as a risk factor, not as the etiologic agent of the condition.

This review focuses on the established clinical measures and ongoing research on the possible interventions aimed at preventing the gradual degeneration of PM related to chronic PD.

\section{UFF prevention}

Peritonitis. Because peritonitis episodes are consistently related to the loss of UF capacity, ${ }^{33}$ adequate prevention and early treatment are essential to the success of the technique. It is believed that compliance with the antiseptic routine is related to a reduction in the number of infectious episodes, ${ }^{34}$ which consequently results in lower dropout rates.

Specific measures to reduce the incidence of peritonitis begin with catheter insertion. These measures include positioning the tip downward, not using stitches to close the exit site wound and using prophylactic intravenous antibiotics, all of which have been shown to decrease infection. . $^{35,36}$

Over the long term, hand washing is crucial for the prevention of contamination; the training nurse is the most important professional for this activity. There is evidence that, in addition to hand washing, topical prophylaxis with mupirocin $^{37,38}$ or gentamycin ${ }^{39}$ reduces peritonitis rates. Because exit site infections are also related to peritoneal cavity infections, early and aggressive treatment of exit site lesions and infections should be started as soon as the first signs appear and should be maintained until the lesion or infection has been resolved. ${ }^{40}$

Avoiding contamination from other sources through antibiotic prophylaxis is also recommended when invasive procedures are performed and when there is another intraabdominal source of contamination.

Liquid and salt balance. It is prudent to frequently remind PD patients of the importance of fluid and salt restriction because the ability of the kidneys to reach a neutral sodium balance is diminished with the loss of RRF.

In PD, sodium removal occurs through diffusive transport with glucose-based solutions. When icodextrin is employed, convective transport contributes to global sodium loss as well. ${ }^{41}$ In the initial phase of the glucosebased fluid dwell, the osmotic gradient is maximal, and intense osmotic water transport occurs through the ultrasmall pores (AQP1), leading to sodium sieving. Sodium sieving is a consequence of the exclusive traffic of water free of solutes, leaving significant sodium loss restricted to the later phase of the dwell. ${ }^{4}$ The shorter the prescribed dwells are, the more important sodium retention becomes. Clinically, patients treated with automated peritoneal dialysis (APD) tend to lose less sodium than patients treated with chronic ambulatory peritoneal dialysis (CAPD) due to the short night dwells. ${ }^{42,43}$ For APD patients, sodium restriction is even more important in achieving sodium and fluid balance. With icodextrin, the removal of salt through convection can be enhanced because with every $100 \mathrm{~mL}$ of UF, approximately $0.9 \mathrm{mg}$ of sodium chloride is removed. ${ }^{44}$ 
In individuals who respond, who are generally those with residual clearance, the use of high-dose loop diuretics may help in achieving dry weight through an increase in renal fluid and sodium excretion without an additional increase in the glucose load - a measure that does not interfere in RRF. ${ }^{45,46}$

Initial and continuous counseling regarding the importance of complying with the dietary restrictions and adjusting these recommendations according to RRF loss over time may allow the prescription of fewer antihypertensive drugs ${ }^{47}$ and a lower glucose concentration to promote adequate osmosis and maintain dry weight. To ensure an objective approach to patient management, the reassessment of dietary intake and the renal component of $\mathrm{Kt} / \mathrm{V}$ (RRF) should be routine practice.

Dialysis fluids. In most countries, glucose is the primary osmotic agent used in PD. It has been demonstrated that glucose acts as a promoter of angiogenesis and fibrosis in the peritoneal cavity in a manner similar to that seen in damaged end-organs in diabetes. ${ }^{48,49}$ The greater the necessity to promote UF, which is related to the RRF and fluid and salt ingestion, the bigger the required glucose load. Also important is the baseline small-solute transfer rate of an individual patient, which influences the glucose load prescribed by the nephrologist. ${ }^{10}$ As the speed of solute transport and the dissipation of the osmotic gradient increase, the amount of glucose required to obtain adequate fluid balance also increases. Avoiding unnecessary glucose overload in the cavity is recommended during long-term follow-up to prolong the modality lifespan.

Alternatives to glucose have been researched in the last decade, and the glucose polymer icodextrin is already routinely available in some countries. It is an isosmolar compound that promotes UF through colloid osmosis, and its use is currently restricted to 1-2 daily exchanges to avoid systemic accumulation. ${ }^{50}$ In general, it is prescribed for the longest dwell, which is the night dwell in CAPD and the day dwell in APD. A slower decline in peritoneal function over time has been demonstrated with icodextrin than with high glucose concentrations.

The avoidance of glucose-based PDF also helps minimize the exposure of the membrane to GDPs and AGEs, which are also associated with a fast transport profile and UFF. GDPs are toxic to mesothelial cells and lead to the faster formation of AGEs in the membrane than glucose does. ${ }^{51}$ Fluids with neutral $\mathrm{pH}$ and low GDP content lead to an increase in effluent cancer antigen 125 (CA-125), a mesothelial cell mass marker in PD, indicating preservation of the mesothelium. ${ }^{52}$ Minimizing AGEs is also of interest, but it should be remembered that the PDF is not the only source of these molecules; the uremic serum is a site of AGE formation as well, but the peritoneal accumulation of AGEs can be reduced if PDFs with lower glucose concentration are prescribed.

An alternative is to prescribe purely bicarbonate-buffered low-GDP fluids, which seem to improve peritoneal membrane integrity, as indirectly evaluated using human peritoneal mesothelial cell (HPMC) culture; ${ }^{53}$ preserve host defense mechanisms as shown in animal models; ${ }^{54}$ and provide a better effluent marker profile, with lower levels of transforming growth factor- $\beta$ (TGF- $\beta$ ) and vascular endothelial growth factor (VEGF) levels in patients. ${ }^{55}$ However, these fluids are not widely available. Additionally, these fluids seem to have a positive effect on RRF, but it is not yet possible to foresee how the PM of patients will respond over the long term with chronic exposure to these new solutions.

Oxidative stress. Many links have been identified between oxidative stress and the activation of fibrogenic and angiogenic pathways, mostly through TGF- $\beta$ and VEGF. The expression of growth factors induced by GDPs, such as methylglyoxal and acetaldehyde, have been successfully blocked in in vitro and in vivo studies by the antioxidant agents $\mathrm{N}$-acetylcysteine (NAC) ${ }^{56}$ and catalase. ${ }^{57}$ Our group has also shown that NAC prevents PM thickening in vivo ${ }^{58}$. GDPs are precursors of AGEs, which also induce the production of cellular reactive oxygen species (ROS), ${ }^{59,60}$ and ROS in turn promote AGE formation and thus signal amplification. $^{61}$ In the PM, GDPs, and AGEs play an essential role in chronic inflammation when glucose-based fluids are employed, and it has been found that NAC and angiotensin receptor antagonists (ARBs) prevent PDF-induced collagen I and heat shock protein accumulation in the omentum, results that strongly suggest that ROS are major mediators of peritoneal fibrosis. ${ }^{62}$

In addition, cyclooxygenase- 2 inhibitors ${ }^{63}$ and peroxisome proliferator-activated receptor- $\gamma$ (PPAR- $\gamma$ ) antagonists ${ }^{64}$ have been tested in HPMC studies and in animal studies to determine the ability of these drugs to prevent the connection between inflammatory stimuli and profibrotic pathways; positive results have been reported.

The final goal is the translation of these results into clinical practice. In patients, NAC, angiotensin-converting enzyme inhibitors (ACEis) and ARBs have been tested, and the results are discussed in the following sections.

Fibrosis. TGF- $\beta 1$ is the most important cytokine involved in peritoneal fibrosis, and its synthesis in peritoneal mesothelial cells and the synthesis of its receptors are stimulated by bio-incompatible PDFs. ${ }^{65,66,67}$ Interleukin-1 (IL-1) and tumor necrosis factor- $\alpha$ (TNF- $\alpha)$, which are released during peritonitis episodes, also contribute to peritoneal fibrogenesis, probably through the induction of $\mathrm{EMT}^{68}{ }^{6}$ which is a phenomenon experiencing growing interest amongst recent publications. Other cytokines, such as TGF- $\beta 2$, TGF- $\beta 3$, platelet-derived growth factor, fibroblast growth factor-2, and connective tissue growth factor ${ }^{69}$ are involved, together with plasminogen activator inhibitor $-1,{ }^{70}$ in the initiation of fibrosis. There is also evidence that angiotensin II induces fibronectin expression in mesothelial cells via extracellular-signal-regulated kinase 1 (ERK-1), ERK2 and mitogen-activated protein kinase (MAPK) $)^{71,72}$ and that it takes part in the membrane's cellular immune response. ${ }^{73}$

In experiments with cultured HPMCs and animal models, attempts to block fibrosis through interference with these factors have been made, with variable results. Among the tested interventions, positive results for fibrosis and EMT prevention were achieved with bone morphogenic protein$7,{ }^{74}$ emodin, ${ }^{75}$ mammalian target of rapamycin inhibitors, ${ }^{76}$ pentoxifylline, ${ }^{77}$ diltiazem, ${ }^{78}$ tranilast, ${ }^{79}$ and dipyridamole. ${ }^{80}$ In collaboration with Spanish colleagues, we have tested the beta-blocker nebivolol in vivo and have achieved success in reducing fibrogenesis and neoangiogenesis, in the $\mathrm{PM}^{81}$ The adenovirus-mediated gene transfer of decorin has also been tested and was shown to reduce peritoneal collagen content in an animal model of PD. ${ }^{82}$

In addition to the prevention of fibrogenesis, collagen turnover is becoming an object of scrutiny in PD. The matrix metalloproteinases 2 and 9 (MMPs) are gelatinases involved in the regulation of inflammation and in the degradation of 
the extracellular matrix, and thus they facilitate the migration of cells in processes such as EMT. When in excess, MMP activity may impair wound healing. ${ }^{83}$ ACEis have been studied in this context and have shown direct anti-MMP-2 activity in PD by binding to its active site and forming complexes in the drained effluent. ${ }^{84}$ This activity could possibly blunt EMT.

These experiments have been extremely useful in further improving our understanding of UFF pathogenesis independent of the clinical application of the specific drug employed. Comprehension of the involved mechanisms has been essential in adapting PD to peritoneal physiology and in determining which drugs could be beneficial to patients with signs of fibrosis progression and PM degeneration in PD.

Angiogenesis. The inhibition of angiogenesis has been tested in vitro and in vivo in different scenarios, such as wound healing, ${ }^{85}$ carcinoma metastasis, ${ }^{86}$ and PD. ${ }^{82}$ Inhibition has been achieved with anti-proliferative agents such as angiostatin and anti-VEGF antibodies. ${ }^{87}$ In the context of wound healing, slower or incomplete tissue repair has been found to be a consequence of this inhibition. ${ }^{88}$ In carcinomas, the results have been positive, and anti-VEGF antibodies are already clinically available as adjuvant drugs to inhibit the growth and metastases of a variety of tumors.

In vivo, systemic angiogenesis inhibition has been related to different clinically undesirable effects, which differ according to the developmental phase. In adults, one of the most prominent unwanted events is the worsening of or de novo proteinuria, ${ }^{89,90}$ which can lead to additional loss of RRF. In retinal vascular proliferative diseases, however, where AGEs stimulate the expression of VEGF mRNA, ${ }^{91}$ anti-VEGF agents are used locally with success. ${ }^{92}$ The possibility of using locally active agents without systemic side effects is an attractive idea in the management of progressively accelerating small-solute transport because VEGF activation is thought to play an essential role in the observed membrane damage ${ }^{93}$ and because the preservation of RRF is related to survival in dialysis patients. ${ }^{94}$ Experimental protocols are currently under development.

Captopril, enalapril and losartan have also been studied in HPMC culture and have been shown to lead to a decrease in VEGF production after exposure to TNF- $\alpha$ and IL-1. ${ }^{95}$ In humans, a retrospective analysis comparing small-solute transport in 36 patients receiving an ACEis or ARBs with that in 30 controls revealed that in the treated group, smallsolute transport decreased over 2 years of follow-up, whereas transport increased among controls. ${ }^{96}$ Although the available evidence is not considered strong, as discussed in a recent meta-analysis, ${ }^{97,98}$ the use of either ACEis or ARBs in PD patients is commonly advocated to preserve RRF and prevent cardiovascular events.

Most of the experimental protocols targeting the vascular component of UFF pathogenesis are focused on its prevention, and important answers concerning the reversal of established excessive vascularization are still lacking.

\section{UFF reversal}

A few strategies have led to recovery from UFF, including membrane rest involving four weeks of hemodialysis, with which positive results have been obtained in recently diagnosed cases. ${ }^{99,100}$ In addition, in cases of UFF associated with beta-blockers, where scant tissue damage is observed, the reversal of the dysfunction has been described with the discontinuation of the drug. ${ }^{101}$ However, reversal is not guaranteed in severe cases of UFF in which histological damage is clear or when the diagnosis is only made at later stages. A delayed diagnosis can be common in patients with significant RRF who can maintain adequate fluid balance without being dependent on peritoneal clearance. In cases of established tissue damage, such as diffuse fibrosis and significant established neoangiogenesis, no satisfactory clinical or pharmacological intervention has been found.

Mesothelial cell transplantation has been studied as another possibility for promoting PM repair, as these cells play a central role in local inflammatory responses, in the regulation of peritoneal microcirculation and in maintaining the balance between fibrin deposition and degradation. ${ }^{102} \mathrm{~A}$ few studies have been published evaluating this intervention in animals and in humans, ${ }^{103,104,105}$ but activation of the PM, with prolonged inflammation and increased thickness in the early post-transplant phase, has been noticed. ${ }^{106}$ Whether this activation is a result of the cell culturing conditions or of the transplant itself has yet to be established; therefore, the applicability of this technique is not yet clear.

Another possible intervention for the future could be the transplantation of bone marrow-derived cells because markers indicative of their implantation were detected in the PM 7-42 days after their intraperitoneal injection; however, this result is very preliminary, and it is not possible to define the role of bone marrow-derived cells in the context of membrane failure. ${ }^{107}$

\section{CONCLUSION}

In the near future, it is possible that new pharmacological interventions aiming to minimize the occurrence of UFF will emerge as a result of ongoing worldwide research in this field because many of the processes involved in the progression of damage have been unveiled. However, few strategies are available to date. ACEis or BRAs are already frequently prescribed to the PD population in an attempt to preserve RRF and prevent UFF, regardless of the limited available evidence supporting their use. It is desirable to avoid the current bio-incompatible PDFs, which allow immediate control of fluid overload but accelerate the degeneration of the membrane; thus, more compatible fluids must be made available. Adequate training, nutritional advice and surveillance, and patient compliance to the diet and to sterile techniques are already feasible procedures and should be monitored on a routine basis as part of PD preservation strategies.

Collectively, the cited studies show that many distinct parallel event chains can ultimately lead to the fast transporter phenotype and that it is probably necessary to simultaneously block different triggers to effectively minimize inflammation and its local consequences. Beyond considering one factor as the defining step, the balance between the activation of pro- and anti-inflammatory pathways seems to define the final phenotype.

\section{AUTHOR CONTRIBUTIONS}

Aguirre AR was responsible for searching the literature for relevant data, and manuscript writing. Abensur $\mathrm{H}$ was responsible for searching the literature for relevant data, manuscript draft, and manuscript revision.

\section{REFERENCE}

1. Boen ST, Curtis FK, Tenckhoff H, Scribner BH. Chronic hemodialysis and peritoneal dialysis. Proc Eur Dial Transplant Assoc. 1964;1:221-3. 
2. Mehrotra R. Changing patterns of peritoneal dialysis utilization in the United States. Perit Dial Int. 2007;27: S51-S2.

3. Lameire N, Van Biesen W. Epidemiology of peritoneal dialysis: a story of believers and nonbelievers. Nat Rev Nephrol. 2010;6:75-82, doi: 10 . 1038/nrneph.2009.210.

4. Rippe B, Venturoli D, Simonsen O, de Arteaga J. Fluid and electrolyte transport across the peritoneal membrane during CAPD according to the three-pore model. Perit Dial Int. 2004;24:10-27.

5. Rippe B, Stelin G. Simulations of peritoneal solute transport during CAPD. Application of two-pore formalism. Kidney Int. 1989;35:1234-44, doi: $10.1038 / \mathrm{ki} .1989 .115$.

6. Pannekeet MM, Mulder JB, Weening JJ, Struijk DG, Zweers MM, Krediet RT. Demonstration of aquaporin-chip in peritoneal tissue of uremic and CAPD patients. Perit Dial Int. 1996;16:S54-7.

7. Flessner MF, Dedrick RL, Schultz JS. A distributed model of peritonealplasma transport: theoretical considerations. Am J Physiol. 1984;246: 597-607.

8. Kawaguchi Y, Hasegawa T, Nakayama M, Kubo H, Shigematu T. Issues affecting the longevity of the continuous peritoneal dialysis therapy. Kid Int Suppl. 1997;62:S105-S107.

9. Heimbürger $\mathrm{O}$, Waniewski J, Werynski A, Tranaeus A, Lindholm B. Peritoneal transport in CAPD patients with permanent loss of ultrafiltration capacity. Kidney Int. 1990;38:495-506, doi: 10.1038/ki. 1990.231.

10. Mujais S, Nolph K, Gokal R, Blake P, Burkart J, Coles G, et al. Evaluation and management of ultrafiltration problems in peritoneal dialysis. Perit Dial Int. 2000;20:S5-21.

11. Lo WK, Bargman JM, Burkart J, Krediet RT, Pollock C, Kawanishi H, et al. Guideline on targets for solute and fluid removal in adult patients on chronic peritoneal dialysis. Perit Dial Int. 2006;26:520-2.

12. Brown EA, Davies SI, Rutherford P, Meeus F, Borras M, Riegel W, et al. Survival of functionally anuric patients on automated peritoneal dialysis: the European APD outcome study. J Am Soc Nephol. 2003;14: 2948-57, doi: 10.1097/01.ASN.0000092146.67909.E2.

13. Jansen MA, Termorshuizen F, Korevaar JC, Dekker FW, Boeschoten E, Krediet RT, et al. Predictors of survival in anuric peritoneal dialysis patients. Kidney Int. 2005;68:1199-205, doi: 10.1111/j.1523-1755.2005. 00512.x.

14. Krediet RT, Balafa O. Cardiovascular risk in the peritoneal dialysis patient. Nat Rev Nephrol. 2010;6:451-60, doi: 10.1038/nrneph.2010.68.

15. Rutten JH, Korevaar JC, Boeschoten EW, Dekker FW, Krediet RT, Boomsma F, et al. B-Type natriuretic peptide and amino-terminal atrial natriuretic peptide predict survival in peritoneal dialysis. Perit Dial Int. 2006;26:598-602.

16. Fortes PC, de Moraes TP, Mendes JG, Stinghen AE, Ribeiro SC, PecoitsFilho R. Insulin resistance and glucose homeostasis in peritoneal dialysis. Perit Dial Int. 2009;29:S145-8.

17. Chen H-Y, Kao T-W, Huang J-W, Chu T-S, Wu K-D. Correlation of metabolic syndrome with residual renal function, solute transport rate and peritoneal solute clearance in chronic peritoneal dialysis patients. Blood Purif. 2008;26:138-44, doi: 10.1159/000113506.

18. Flessner MF. Peritoneal ultrafiltration: physiology and failure. Contrib. Nephrol. 2009;163:7-14, doi: 10.1159/000223773.

19. Williams JD, Craig KJ, Topley N, Von Ruhland C, Fallon M, Newman GR, et al. Morphologic changes in the peritoneal membrane of patients with renal disease. J Am Soc Nephrol. 2002;13:470-9.

20. Davies SI, Bryan J, Phillips L, Russell GI. Longitudinal changes in peritoneal kinetics: the effects of peritoneal dialysis and peritonitis. Nephrol Dial Transplant. 1996;11:498-506.

21. Ha H, Yu MR, Lee HB. High glucose-induced PKC activation mediates TGF-beta 1 and fibronectin synthesis by peritoneal mesothelial cells. Kidney Int. 2001;59:463-70, doi: 10.1046/j.1523-1755.2001.059002463.x.

22. Witowski J, Wisniewska J, Koryblaska K, Bender TO, Breborowicz A, Gahl GM, et al. Prolonged exposure to glucose degradation products impairs viability and function of human peritoneal mesothelial cells. J Am Soc Nephrol. 2001;12:2434-41.

23. Nakayama M, Kawaguchi Y, Yamada K, Hasegawa T, Takazoe K, Katoh N, et al. Immunohistochemical detection of advanced glycosylation end-products in the peritoneum and its possible pathophysiological role in CAPD. Kidney Int. 1997;51:182-6, doi: 10.1038/ki.1997.22.

24. Aroeira LS, Aguilera A, Sánchez-Tomero JA, Bajo MA, del Peso G, Jiménez-Heffernan JA, et al. Epithelial to mesenchymal transition and peritoneal membrane failure in peritoneal dialysis patients: pathologic significance and potential therapeutic interventions. J Am Soc Nephrol. 2007;18:2004-13, doi: 10.1681/ASN.2006111292

25. Yáñez-Mó M, Lara-Pezzi E, Selgas R, Ramírez-Huesca M, DomínguezJiménez C, Jiménez-Heffernan JA, et al. Peritoneal dialysis and epithelial-to-mesenchymal transition of mesothelial cells. N Engl J Med. 2003;348:403-13, doi: 10.1056/NEJMoa020809.

26. Krediet RT, Lindholm B, Rippe B. Pathophysiology of peritoneal membrane failure. Perit Dial Int. 2000;4:S22-42.

27. Ni J, Verbavatz JM, Rippe A, Boisdé I, Moulin P, Rippe B, et al. Aquaporin-1 plays an essential role in water permeability and ultrafiltration during peritoneal dialysis. Kidney Int. 2006;69:1518-25, doi: 10.1038 /sj.ki.5000285

28. Honda K, Oda H. Pathology of encapsulating peritoneal sclerosis. Perit Dial Int. 2005;25:S19-29.

29. Goodlad C, Brown EA. Encapsulating Peritoneal Sclerosis: What Have We Learned? Seminars in Nephrology. 2011;31:183-98, doi: 10.1016/j. semnephrol.2011.01.007.

30. Garosi G, Di Paolo N, Sacchi G, Gaggiotti E. Sclerosing peritonitis: a nosological entity. Perit Dial Int. 2005;25:S110-2.

31. Odama UO, Shih DJ, Korbet SM. Sclerosing peritonitis and systemic lupus erythematosus: a report of two cases. Perit Dial Int. 1999;19:160-4.

32. Garosi G, Di Paolo N. Peritoneal sclerosis: one or two nosologica entities? Semin Dial. 2000;13:297-308, doi: 10.1046/j.1525-139x.2000. 00080.x.

33. Voinescu CG, Khanna R. Peritonitis in peritoneal dialysis. Int J Artif Organs. 2002;25:249-60.

34. Bender FH, Bernardini J, Piraino B. Prevention of infectious complications in peritoneal dialysis: best demonstrated practices. Kidney Int Suppl. 2006;70:S44-54, doi: 10.1038/sj.ki.5001915.

35. Flanigan M, Gokal R. Peritoneal catheters and exit-site practices toward optimum peritoneal access: a review of current developments. Perit Dial Int. 2005;25:132-9.

36. Lye WC, Lee EJ, Tan CC. Prophylactic antibiotics in the insertion of Tenckhoff catheters. Scand J Urol Nephrol. 1992;26:177-80.

37. Thodis E, Passadakis P, Panagoutsos S, Bacharaki D, Euthimiadou A Vargemezis V. The effectiveness of mupirocin preventing Staphylococcus aureus in catheter-related infections in peritoneal dialysis. Adv Perit Dial. 2000;16:257-61.

38. Bernardini J, Piraino B, Holley J, Johnston JR, Lutes R. A randomized trial of staphylococcus aureus prophylaxis in peritoneal dialysis patients: Mupirocin calcium ointment $2 \%$ applied to the exit site versus cyclic oral rifampin. Am J Kidney Dis. 1996;27:695-700, doi: 10.1016/ S0272-6386(96)90105-5.

39. Sheth HS, Bernardini J, Bender F, Piraino B. Follow-up evaluation of gentamicin cream prophylaxis for peritoneal dialysis catheter infections. Perit Dial Int. 2007;27:S26-c.

40. Vychytil A, Lorenz M, Schneider B, Hörl WH, Haag-Weber M. New criteria for management of catheter infections in peritoneal dialysis patients using ultrasonography. J Am Soc Nephrol. 1998;9:290-6.

41. Van Biesen W, Vanholder R, Veys N, Lameire N. Improving salt balance in peritoneal dialysis patients. Perit Dial Int. 2005;25:S73-5

42. Ortega O, Gallar P, Carreño A, Gutierrez M, Rodriguez I, Oliet A, et al. Peritoneal sodium mass removal in continuous ambulatory peritoneal dialysis and automated peritoneal dialysis: Influence on blood pressure control. Am J Nephrol. 2001;21:189-93, doi: 10.1159/000046246.

43. Rodríguez-Carmona A, Fontán MP. Sodium removal in patients undergoing CAPD and automated peritoneal dialysis. Perit Dial Int. 2002;22:705-13.

44. Konings CJ, Kooman JP, Schonk M, Gladziwa U, Wirtz J, van der Wall Bake AW, et al. Effect of icodextrin on volume status, blood pressure and echocardiographic parameters: A randomized study. Kidney Int. 2003;63:1556-63, doi: 10.1046/j.1523-1755.2003.00887.x.

45. van Olden RW, Guchelaar HJ, Struijk DG, Krediet RT, Arisz L. Acute effects of high dose furosemide on residual renal function in CAPD patients. Perit Dial Int. 2003;23:339-47.

46. Medcalf JF, Harris KP, Walls J. Role of diuretics in the preservation of residual renal function in patients on CAPD. Kidney Int. 2001;59:112833, doi: 10.1046/j.1523-1755.2001.0590031128.x.

47. Günal AI, Duman S, Özkahya M, Töz H, Asci G, Akçiçek F, et al. Strict volume control normalizes hypertension in peritoneal dialysis patients. Am J Kidney Dis. 2001;37:588-93, doi: 10.1016/S0272-6386(01)80017-2.

48. Krediet RT, Zweers MM, van der Wal AC, Struijk DG. Neoangiogenesis in the peritoneal membrane. Perit Dial Int. 2000;20:S19-25.

49. Mateijsen MA, van der Wal AC, Hendriks PM, Zweers MM, Mulder J, Struijk DG, et al. Vascular and interstitial changes in the peritoneum of CAPD patients with peritoneal sclerosis. Perit Dial Int. 1999;19:517-25.

50. Sav T, Oymak O, Inanc MT, Dogan A, Tokgoz B, Utas C. Effects of twice-daily icodextrin administration on blood pressure and left ventricular mass in patients on continuous ambulatory peritoneal dialysis. Perit Dial Int. 2009;29:443-9.

51. Wieslander AP, Andrén AH, Nilsson-Thorell C, Muscalu N, Kjellstrand PT, Rippe B. Are aldehydes in heat-sterilized peritoneal dilaysis fluids toxic in vitro? Perit Dial Int. 1995;15:348-52.

52. Jones S, Holmes CJ, Krediet RT, Mackenzie R, Faict D, Tranaeus A, et al. Bicarbonate/lactate-based peritoneal dialysis solution increases cancer antigen 125 and decreases hyaluronic acid levels. Kidney Int. 2001;59:1529-38, doi: 10.1046/j.1523-1755.2001.0590041529.x.

53. Grossin N, Wautier MP, Wautier JL, Gane P, Taamma R, Boulanger E. Improved in vitro biocompatibility of bicarbonate-buffered peritoneal dialysis fluid. Peritl Dial Int. 2006;26:664-70.

54. Mortier S, De Vriese AS, Mcloughlin RM, Topley N, Schaub TP, Passlick-Deetjen J, et al. Effects of conventional and new peritoneal dialysis fluids on leukocyte recruitment in the rat peritoneal membrane. 
J Am Soc Nephrol. 2003;14:1296-306, doi: 10.1097/01.ASN.0000060681. 91079.30.

55. Williams JD, Topley N, Craig KJ, Mackenzie RK, Pischetsrieder M, Lage C, et al. The Euro-Balance Trial: the effect of a new biocompatible peritoneal dialysis fluid (Balance) on the peritoneal membrane. Kidney Int. 2004;66:408-18, doi: 10.1111/j.1523-1755.2004.00747.x.

56. Che W, Asahi M, Takahashi M, Kaneto H, Okado A, Higashiyama S, et al. Selective induction of heparin-binding epidermal growth factorlike growth factor by methylglyoxal and 3-deoxyglucosone in rat aortic smooth muscle cells: The involvement of reactive oxygen species formation and a possible implication for atherogenesis. J Biol Chem. 1997:272:18453-9, doi: 10.1074/jbc.272.29.18453.

57. Greenwel P, Domínguez-Rosales JA, Mavi G, Rivas-Estilla AM, Rojkind M. Hydrogen peroxide: A link between acetaldehyde-elicited $\alpha 1$ (I) collagen gene up-regulation and oxidative stress in mouse hepatic stellate cells. Hepatology. 2000;31:109-16, doi: 10.1002/hep.510310118.

58. Bui DS, Seguro AC, Shimitzu MH, Schliemann I, Martini D, Romão JE, et al. N-Acetylcisteine protects the peritoneum from the injury induced by hypertonic dialysis solution. J Nephrol. 2011 in press.

59. Yim MB, Yim HS, Lee C, Kang SO, Chock PB. Protein glycation: creation of catalytic sites for free radical generation. Ann N Y Acad Sci. 2001;928:48-53, doi: 10.1111/j.1749-6632.2001.tb05634.x.

60. Wautier MP, Chappey O, Corda S, Stern DM, Schmidt AM, Wautier JL. Activation of NADPH oxidase by AGE links oxidant stress to altered gene expression via RAGE. Am J Physiol Endocrinol Metab. 2001;280:E685-94

61. Nishikawa T, Edelstein D, Du XL, Yamagishi S, Matsumura T, Kaneda Y, et al. Normalizing mitochondrial superoxide production blocks three pathways of hyperglycaemic damage. Nature. 2000;404:787-90, doi: 10 . $1038 / 35008121$

62. Noh H, Kim JS, Han KH, Lee GT, Song JS, Chung SH, et al. Oxidative stress during peritoneal dialysis: Implications in functional and structural changes in the membrane. Kidney Int. 2006;69:2022-8, doi: 10.1038/sj.ki.5001506.

63. Aroeira LS, Lara-Pezzi E, Loureiro J, Aguilera A, Ramírez-Huesca M, González-Mateo G, et al. Cyclooxygenase-2 mediates dialysate-induced alterations of the peritoneal membrane. J Am Soc Nephrol. 2009;20:58292, doi: 10.1681/ASN.2008020211.

64. Sandoval P, Loureiro J, González-Mateo G, Pérez-Lozano ML, Maldonado-Rodríguez A, Sánchez-Tomero JA, et al. PPAR-gamma agonist rosiglitazone protects peritoneal membrane from dialysis fluidinduced damage. Lab Invest. 2010;90:1517-32, doi: 10.1038/labinvest. 2010.111.

65. Naiki Y, Maeda Y, Matsuo K, Yonekawa S, Sakaguchi M, Iwamoto I, et al. Involvement of TGF-beta signal for peritoneal sclerosing in continuous ambulatory peritoneal dialysis. J Nephrol. 2003;16:95-102.

66. Kim YS, Kim BC, Song CY, Hong HK, Moon KC, Lee HS. Advanced glycosylation end products stimulate collagen mRNA synthesis in mesangial cells mediated by protein kinase $C$ and transforming growth factor-beta. J Lab Clin Med. 2001;138:59-68, doi: 10.1067/mlc.2001. 115494.

67. Kang DH, Hong YS, Lim HJ, Choi JH, Han DS, Yoon KI. High glucose solution and spent dialysate stimulate the synthesis of transforming growth factor- $\beta 1$ of human peritoneal mesothelial cells: effect of cytokine costimulation. Perit Dial Int. 1999;19:221-30.

68. Margetts PJ, Kolb M, Galt T, Hoff CM, Shockley TR, Gauldie J. Gene transfer of transforming growth factor-beta1 to the rat peritoneum: effects on membrane function. J Am Soc Nephrol. 2001;12:2029-39.

69. Moussad EE, Brigstock DR. Connective tissue growth factor: what's in a name? Mol Genet Metab. 2000;71:276-92, doi: 10.1006/mgme.2000.3059.

70. Rougier JP, Guia S, Hagège J, Nguyen G, Ronco PM. PAI-1 secretion and matrix deposition in human peritoneal mesothelial cell cultures: transcriptional regulation by TGF-beta 1. Kidney Int. 1998;54:87-98, doi: 10.1046/j.1523-1755.1998.00955.x

71. Noh H, Ha H, Yu MR, Kim YO, Kim JH, Lee HB. Angiotensin II mediates high glucose-induced TGF-beta1 and fibronectin upregulation in HPMC through reactive oxygen species. Perit Dial Int. 2005;25:38-47.

72. Kiribayashi K, Masaki T, Naito T, Ogawa T, Ito T, Yorioka N, et al. Angiotensin II induces fibronectin expression in human peritoneal mesothelial cells via ERK1//2 and p38 MAPK. Kidney Int. 2005;67: 1126-35, doi: 10.1111/j.1523-1755.2005.00179.x

73. Belline P, da Melo PS, Haun M, Palhares FB, Boer PA, Gontijo JA, et al. Effect of angiotensin II and losartan on the phagocytic activity of peritoneal macrophages from Balb/C mice. Mem Inst Oswaldo Cruz. 2004;99:167-72, doi: 10.1590/S0074-02762004000200009.

74. Loureiro J, Schilte M, Aguilera A, Albar-Vizcaíno P, Ramírez-Huesca M, Pérez-Lozano ML, et al. BMP-7 blocks mesenchymal conversion of mesothelial cells and prevents peritoneal damage induced by dialysis fluid exposure. Nephrol Dial Transplant. 2010;25:1098-108, doi: 10. 1093/ndt/gfp618.

75. Chan TM, Leung JK, Tsang RC, Liu ZH, Li LS, Yung S. Emodin ameliorates glucose-induced matrix synthesis in human peritoneal mesothelial cells. Kidney Int. 2003;64:519-33, doi: 10.1046/j.1523-1755. 2003.00113.x
76. Patel P, Sekiguchi Y, Oh KH, Patterson SE, Kolb MR, Margetts PJ. Smad3-dependent and -independent pathways are involved in peritoneal membrane injury. Kidney Int. 2010;77:319-28, doi: 10.1038/ki.2009. 436.

77. Hung KY, Huang JW, Chen CT, Lee PH, Tsai TJ. Pentoxifylline modulates intracellular signalling of TGF-beta in cultured human peritoneal mesothelial cells: implications for prevention of encapsulating peritoneal sclerosis. Nephrol Dial Transplant. 2003;18:670-6, doi: 10. 1093/ndt/gfg141.

78. Fang CC, Yen CJ, Chen YM, Chu TS, Lin MT, Yang JY. Diltiazem suppresses collagen synthesis and IL-1beta-induced TGF-beta1 production on human peritoneal mesothelial cells. Nephrol Dial Transpl 2006;21:1340-7.

79. Kaneko K, Hamada C, Tomino Y. Peritoneal fibrosis intervention. Perit Dial Int. 2007;27:S82-6.

80. Hung KY, Chen CT, Huang JW, Lee PH, Tsai TJ, Hsieh BS. Dipyridamole inhibits TGF-beta-induced collagen gene expression in human peritoneal mesothelial cells. Kidney Int. 2001;60:1249-57, doi: 10. 1046/j.1523-1755.2001.00933.x

81. Aguirre AR, González-Mateo G, Abensur H, Albar-Vizcaíno P, PérezLozano ML, Selgas R, et al. Nebivolol (NV) prevents peritoneal membrane (PM) failure induced by peritoneal dialysis (PD) fluids. SA-PO2652. In 2010 ASN Renal Week; Denver, CO.

82. Margetts PJ, Gyorffy S, Kolb M, Yu L, Hoff CM, Holmes CJ, et al. Antiangiogenic and antifibrotic gene therapy in a chronic infusion model of peritoneal dialysis in rats. J Am Soc Nephrol. 2002;13:721-8.

83. Xue M, Le NT, Jackson CJ. Targeting matrix metalloproteases to improve cutaneous wound healing. Expert Opin Ther Targets. 2006; 10:143-55, doi: 10.1517/14728222.10.1.143.

84. Yamamoto D, Takai S, Hirahara I, Kusano E. Captopril directly inhibits matrix metalloproteinase-2 activity in continuous ambulatory peritoneal dialysis therapy. Clin Chim Acta. 2010;411:762-4, doi: 10.1016/j.cca. 2010.02.059.

85. Ekici Y, Emiroglu R, Ozdemir H, Aldemir D, Karakayali H, Haberal M. Effect of rapamycin on wound healing: An experimental study. Transplant Proc. 2007;39:1201-3, doi: 10.1016/j.transproceed.2007.04. 013.

86. O'Reilly MS, Holmgren L, Shing Y, Chen C, Rosenthal RA, Moses M, et al. Angiostatin: A novel angiogenesis inhibitor that mediates the suppression of metastases by a Lewis lung carcinoma. Cell. 1994;79: 315-28, doi: 10.1016/0092-8674(94)90200-3.

87. Ferrara N, Hillan KJ, Novotny W. Bevacizumab (Avastin), a humanized anti-VEGF monoclonal antibody for cancer therapy. Biochem Biophys Res Commun. 2005;33:328-35, doi: 10.1016/j.bbrc.2005.05.132.

88. Schäffer M, Schier R, Napirei M, Michalski S, Traska T, Viebahn R. Sirolimus impairs wound healing. Langenbecks Arch Surg. 2007;392: 297-303, doi: 10.1007/s00423-007-0174-5.

89. Hara A, Wada T, Furuichi K, Sakai N, Kawachi H, Shimizu F, et al. Blockade of VEGF accelerates proteinuria, via decrease in nephrin expression in rat crescentic glomerulonephritis. Kidney Int. 2006;69: 1986-95, doi: 10.1038/sj.ki.5000439.

90. Izzedine H, Massard C, Spano JP, Goldwasser F, Khayat D, Soria JC. VEGF signalling inhibition-induced proteinuria: Mechanisms, significance and management. Eur J Cancer. 2010;46:439-48, doi: 10.1016/j. ejca.2009.11.001.

91. Lu M, Kuroki M, Amano S, Tolentino M, Keough K, Kim I, et al. Advanced glycation end products increase retinal vascular endothelial growth factor expression. J Clin Invest. 1998;101:1219-24, doi: 10.1172/ JCI1277.

92. Arevalo JF, Sanchez JG, Lasave AF, Wu L, Maia M, Bonafonte S, et al. Intravitreal bevacizumab (Avastin) for diabetic retinopathy: The 2010 GLADAOF lecture. J Ophthalmol. 2011;2011:1-13, doi: 10.1155/2011/ 584238.

93. De Vriese AS, Tilton RG, Stephan CC, Lameire NH. Vascular endothelial growth factor is essential for hyperglycemia-induced structural and functional alterations of the peritoneal membrane. J Am Soc Nephrol. 2001;12:1734-41.

94. Wang AY. The "heart" of peritoneal dialysis: residual renal function. Perit Dial Int. 2007;27:116-24.

95. Sauter M, Cohen CD, Wörnle M, Mussack T, Ladurner R, Sitter T. Ace inhibitor and AT-1-receptor blocker attenuate the production of VEGF in mesothelial cells. Perit Dial Int. 2007;27:167-72.

96. Kolesnyk I, Dekker FW, Noordzij M, le Cessie S, Struijk DG, Krediet RT. Impact of ACE inhibitors and AII receptor blockers on peritoneal membrane transport characteristics in long-term peritoneal dialysis patients. Perit Dial Int. 2007;27:446-53.

97. Zannad F, Kessler M, Lehert P, Grünfeld JP, Thuilliez C, Leizorovicz A, et al. Prevention of cardiovascular events in end-stage renal disease: results of a randomized trial of fosinopril and implications for future studies. Kidney Int. 2006;70:1318-24, doi: 10.1038/sj.ki.5001657.

98. Akbari A, Knoll G, Ferguson D, McCormick B, Davis A, Biyani M. Angiotensin-converting enzyme inhibitors and angiotensin receptor blockers in peritoneal dialysis: systematic review and meta-analysis of randomized controlled trials. Perit Dial Int. 2009;29:554-61. 
99. de Alvaro F, Castro MJ, Dapena F, Bajo MA, Fernandez-Reyes MJ, Romero JR, et al. Peritoneal resting is beneficial in peritoneal hyperpermeability and ultrafiltration failure. Adv Perit Dial. 1993;9:56-61.

100. Rodrigues A, Cabrita A, Maia P, Guimarães S. Peritoneal rest may succesfully recover ultrafiltration in patients who develop peritoneal hyperpermeability with time on continuous ambulatory peritoneal dialysis. Adv Perit Dial. 2002;18:78-80.

101. Stegmayr BG. Beta-blockers may cause ultrafiltration failure in peritoneal dialysis patients. Perit Dial Int. 1997;17:541-5.

102. Mutsaers SE. Mesothelial cells: their structure, function and role in serosal repair. Respirology. 2002;7:171-91, doi: 10.1046/j.1440-1843.2002.00404.x.

103. Di Paolo N, Sacchi G, Vanni L, Corazzi S, Terrana B, Rossi P, et al. Autologous peritoneal mesothelial cell implant in rabbits and peritoneal dialysis patients. Nephron. 1991;57:323-31, doi: 10.1159/000186283.
104. Nagy JA, Shockley TR, Masse EM, Harvey VS, Jackman RW. Mesothelial cell-mediated gene therapy: feasibility of an ex vivo strategy. Gene Ther. 1995;401:393-401.

105. Hekking LH, Harvey VS, Havenith CE, van den Born J, Beelen RH, Jackman RW, et al. Mesothelial cell transplantation in models of acute inflammation and chronic peritoneal dialysis. Perit Dial Int. 2003;23: 323-30.

106. Hekking LH, Zweers MM, Keuning ED, Driesprong BA, de Waart DR, Beelen RH, et al. Apparent successful mesothelial cell transplantation hampered by peritoneal activation. Kidney Int. 2005;68:2362-7, doi: 10 . 1111/j.1523-1755.2005.00698.x.

107. Sekiguchi Y, Hamada C, Inaba M, Shimaoka T, Ro Y, lo H, et al. Roles of bone marrow derived cells in development of morphological alterations in the peritoneum. Perit Dial Int. 2006;26(suppl 2):S20. 